\title{
Improving the Ability of Predictive Thinking
}

\begin{abstract}
Aiming Yu*
Information and Communication College, National University of Defense Technology, Wuhan 430010, Hubei Province, China

*Corresponding author: Aiming Yu, yam01@ sina.com

Abstract: Improving the ability of predictive thinking is conducive in seeking the future and mastering initiative. In order to improve the ability of predictive thinking, it is necessary to strengthen the spirit of active exploration to give full play to people's subjective initiative. Scientific methodology is the basis for improving this ability. It is necessary to learn and apply dialectical materialist methodology and to master advanced methods in specific subject areas. A deep and broad knowledge system is the fundamental for the development of predictive thinking, hence a deep professional knowledge system and a broad multifield knowledge reserve must be formed. The development of science and technology provides traction in discovering new forecasting directions, more advanced tools for forecasting research, and philosophical epistemological guidance for forecasting. Therefore, there is a need to pay great attention to the development of science and technology.
\end{abstract}

Keywords: Prediction; Thinking; Ability

Publication date: July 2021; Online publication: July 30, 2021

\section{Introduction}

Preparedness ensures success, unpreparedness spells failure. Only by scientific prediction, one can plan ahead, seek the future, and take initiative. Cultivating the quality of predictive thinking and improving the ability of this thinking help individuals plan their lives and achieve their careers, help companies or units to win competitions and move forward steadily, as well as help countries and nations to prosper and stand firm in an invincible position.

\section{Strengthening long-term initiative and the spirit of exploration}

Predictive thinking is the thinking activity of judging the future based on present speculations and judging the unknown based on known speculations. It is a subjective activity of human beings. In order to improve the ability of predictive thinking, the first is to strengthen the consciousness of active exploration of the predictor, pay attention to the future, actively seek things, and be brave in exploring. Only then, can accurate predictions be possible in providing reliable basis for scientific decision-making.

\subsection{Strengthening long-term initiative}

In order to improve predictive thinking ability, first of all, there is a need to have the initiative and consciousness to seek long-term careers. Specifically, an individual needs to be willing to explore the general trend of historical development, take the initiative in paying attention, examining, and grasping the future, have the courage to step out of their comfort zone, seize development opportunities, and strive for development initiatives. There are many factors that affect the development of things; hence, it is difficult to predict risks. In cultivating calmness for success as part of an individual's responsibility, there is a need to respect the objective foundation, be able to abstain from impetuosity, be down-to-earth, and settle down 
in certain specific and practical work such as data collection and arrangements, learning forecasting methods, etc. After being tempered, the individual would then be able to withstand loneliness, explore the essence, and summarize the laws to provide a reliable basis for scientific decision-making.

\subsection{Strengthening the spirit of exploration}

Predictive thinking is the understanding and grasp of the essential attributes and characteristics of the law of things. The essential attributes and characteristics of the law of things are always hidden behind apparent appearances. There is a need to examine and analyze them in order to identify the inevitable and accidental. Therefore, using laws to predict the future and unknown requires a strong spirit of exploration. This kind of exploration does not simply use history to deduce the current situation, use the past to deduce the future, finiteness to derive infinity, the known to derive the unknown, neither it uses static to derive dynamics but it requires one to comprehensively think, scientifically judge, logically reason, and firmly understand. One should then stay true to the nature of things, comprehend new situations and problems that may arise, as well as explore the possible trajectory of the development of things to form scientific and accurate predictions.

\section{Mastering scientific methodology}

Scientific methodology is the basis for improving the ability of predictive thinking. Improving the ability of predictive thinking is inseparable from the guidance of the universal regularity theory at the method level. Methodology is a philosophical summary of all the methods and experiences in human research of various fields such as nature, society, and thinking. It is the method that is generally applicable in various disciplines and fields. Methodology cannot be directly applied to a specific predicted problem, but it helps find inherent contradictions of the problem and provides a theoretical basis for selecting an appropriate and effective prediction method for that specific problem. As the systems theory believes, complex systems are unpredictable ${ }^{[1]}$. Hence, one should not extravagantly expect to predict the definite future of complex systems but to predict the various possibilities of the future.

\subsection{Learn and apply dialectical materialist methodology}

The methodology of dialectical materialism is a scientific methodology that continues to develop along with the development of practice, and it has an overall guiding and enlightening effect on all forecasting problems. Xuesen Qian has stated ${ }^{[2]}$, “Always try to use Marxist philosophy to guide work." Therefore, the prediction of any problem is inseparable from the guidance and enlightenment of the dialectical materialist methodology. For example, the method of seeking truth from facts implies that for any prediction problem, one must first clarify the relationship between all the research objects with the internal and external elements (facts) then, proceed to remove the rough from the essence, remove the false and save the truth from the external research (seeking) to obtain an internal, stable and inevitable connection of various factors, namely the law and then, accurately predict the development of things according to it. Mastering the general principles of dialectical materialism methodology and applying it in combination with the practice of forecasting can greatly improve the ability of predictive thinking.

\subsection{Master advanced methods in specific subject areas}

In the actual practice of forecasting, one must use general methodology yet special methods and means are also required. These special methods and means focus on the specific and special nature, situation, and requirements of the prediction object, as well as specifically solve the problems in the prediction. Using Newtonian mechanics and calculus methods, it is possible to predict the time of sunset, solar eclipse, comet 
return, and other celestial phenomena, even the existence of celestial Neptune can be predicted before human observation. Scientists have used the reduction theory to predict the existence of Higgs boson which has been proven in 2013. The Newtonian scientific paradigm which is unimpeded in the prediction of natural sciences has been repeatedly broken down in the prediction of social sciences and complex systems. For example, the forecast of the number of casualties in the United States before the Iraq War is very different from that of the actual situation. The reason is that the forecasting method has difficulties to meet the special needs of complex systems. All living systems including animal-organized groups and humandominated systems such as social, economic, and war systems are considered complex systems with the characteristics of " $1+1 \neq 2$ " in which their predictions are complex. However, there are new methods of complexity science such as network, big data, and deep learning. Of course, the prediction of specific problems also requires more specific forecasting methods and models which include the comprehensive application of multiple forecasting methods and models as well as the mutual comparison of multiple forecasting results leading to more reliable results.

\section{Building a deep and extensive knowledge system}

Predictive thinking is the process of speculation and judgment made by predictors in regard to the future development of things, new things that may occur, or existing things that have not been discovered yet. It is a thinking activity that processes all kinds of information that enters the mind. Therefore, a deep and broad knowledge system is the fundamental for the development of predictive thinking and it is also the basic requirement to improve this ability.

\subsection{Sophisticated professional knowledge system}

Predictive thinking is the process of discovering and applying the law of the development of things. The difficulties and key questions are on how to discover these laws, what intelligence, data, and information that needs to be collected, how to collect these intelligence, data, and information, as well as to clarify the relationship between the various elements so as to determine an inevitable, stable, and inherent essence. All these require experience, theory, professional knowledge, and professional thinking. In the war to resist US aggression and aid Korea, the United Nations military was pessimistic due to three consecutive defeats. Matthew Bunker Ridgway used a commander's professional perspective to analyze and summarize the operational rules of the army's "week offensive" which resulted in a big loss for the army. Similarly, the use of laws to predict the future is by no means a simple repetition and analogy of the past but it is to grasp new conditions and characteristics that will affect the future by taking into account the turning points and the development of things. In order to achieve this, it is very important for forecasters to intensively cultivate and accumulate. A unique insight is inseparable from the "magnifying glass" of professional theory while the "telescope" of professional perspective is inseparable from viewing the micro-knowledge, the original, and the end. It is not common to see what is unusual or familiar to hear what is different which are inseparable from the professional "filter" of literacy. In short, professional people do professional things and improving their professional level is the focus and power tool to improve the ability of predictive thinking.

\subsection{Extensive reserves of knowledge in multiple fields}

Although Kodak faced bankruptcy, their quality of films is still the best in the world. They did not lose to their peers but to digital. The lack of peripheral knowledge limits the field of vision. Extensive multidomain knowledge and in-depth professional knowledge are not contradictory but are dialectically unified. Interlacing is not separating whereby the fields of expertise are different but the principles of "why" and 
"how to do" are the same. The theoretical knowledge, experience, and lessons in other fields can provide epistemological and methodological guidance for research in this field. Ren Zhengfei, the CEO of Huawei prefers to look at commercial competitions in the military perspective. Extensive multi-domain knowledge can provide a rich external environment for forecasting in professional fields and to better look beyond the system. Gödel's incompleteness theorems proved that some things that cannot be solved inside the system need to be solved in a larger system outside. An extensive knowledge of multiple domains allows predictors to "jump out and stand outside the well to see the sky." The fact is true as long as the major prediction results are the results of experts in multiple fields. Russia's top think tank, Primakov and his masterpiece, the World Global Forecast in 2035 has more than 70 participants all of whom are academicians, professors, doctors, associate doctors, and other high-end talents in the fields of economics, politics, history, engineering, communications, and other fields. It can be seen that expanding knowledge and broadening horizons are important conditions for improving the ability of predictive thinking.

\section{Emphasizing on the development of science and technology}

The development of science and technology affects or even restricts the direction and method of the development of things, thereby affecting the development trend of existing things. In view of that, emphasizing on the development of science and technology can improve predictive thinking ability from many aspects.

\subsection{Provide traction to discover new forecasting directions}

On the one hand, the development of science and technology has enabled mankind to have a more comprehensive and in-depth understanding of the world; turning the unknown world into a known world. This newly recognized world has bred huge interests and competitions. Only by studying the laws of spatial development in new fields and grasping their development trends can one advance and master the initiative which in turn is the fundamental driving force for forecasting. On the other hand, the development of science and technology will often change the development trajectory of a field in which it changes or even subverts the competitive landscape of the field. In the past, physical stores have been eliminated by ecommerce while newsstands and telephone booths have been replaced by the internet and mobile phones. In today's society, such examples abound. It can be boldly predicted that with essential conventional technologies, cutting-edge leading technologies, modern engineering technologies, and innovative technology development in many fields, there would be frequent examples of the former foresight whereby the first mover would dominate everything whereas the slower ones would be out of the game ${ }^{[3]}$. Paying attention to the development of science and technology helps people see what they have not seen before, know what they have not known, and improve their predictive thinking ability.

\subsection{Provide more advanced tools for predictive research}

The development of science and technology is the development of understanding the laws of the world as well as the development of research and exploration tools. The development of tools objectively provides more scientific method options for predictions. For example, in the field of criminal investigation, the development of genetic technology has made it possible to solve cases that have lasted for more than a decade and arrest the suspects at once. In addition, criminals do not have a hiding place with the ubiquitous Skynet and big data comparison technology. Paying attention to the development of science and technology as well as strengthening the learning of new tools are important means to improve the ability of predictive thinking. 


\subsection{Provide guidance on philosophical epistemological methodology for forecasting}

If the epistemological methodology is wrong, no matter how much effort is made, it will be totally different. However, if the epistemological methodology is correct, the forecasting work may be more effective. The development of science and technology promotes the development of philosophical epistemological methodology. Born once said ${ }^{[4]}$, "Each stage of science interacts with the philosophical system at that time. Science provides observational facts for the philosophical system and at the same time accepts methods of thinking from philosophy." The three discoveries in the 19th century promoted the transformation of mechanical materialism into dialectical materialism. The highly integrated development of modern science gave birth to new methodologies such as system theory and information theory. The emergence of system theory has provided basic guidance for examining and predicting complex giant systems. Of course, the development of science and technology would yield newer and more scientific epistemological methodology, hence providing further scientific guidance for the development of predictions.

\section{Disclosure statement}

The author declares that there is no conflict of interest.

\section{References}

[1] $\mathrm{Hu} X, 2020$, Science of War, Science Press, 101.

[2] Tu Y, 2007, Qian Xuesen Epistles (V5), National Defense Industry Press, Beijing, 4.

[3] $\mathrm{Xi} \mathrm{J,} \mathrm{2017,} \mathrm{Report} \mathrm{at} \mathrm{the} \mathrm{19th} \mathrm{National} \mathrm{Congress} \mathrm{of} \mathrm{the} \mathrm{Communist} \mathrm{Party} \mathrm{of} \mathrm{China.}$ http://www.xinhuanet.com/politics/19cpcnc/2017-10/27/c_1121867529.htm

[4] Born M, 2015, Physics of Our Generation, The Commercial Press, 50. 